\title{
Smoking cessation interventions after Acute Coronary Syndromes. Results of a cross-sectional survey in the Lazio Region of Italy
}

\author{
Interventi per la cessazione del fumo dopo Sindrome \\ Coronarica Acuta: risultati di uno studio osservazionale \\ trasversale nella Regione Lazio
}

\author{
Furio Colivicchi1, David Mocini1, Massimo Uguccioni2, Stefano Strano3, \\ Giuseppe Imperoli4 and Massimo Santini 1 \\ for the ANMCO (Associazione Nazionale Medici Cardiologi Ospedalieri) Lazio \\ "Smoking Cessation Initiative"
}

\begin{abstract}
Smoking cessation interventions after Acute Coronary Syndromes. Results of a cross-sectional survey in the Lazio Region of Italy. F. Colivicchi, D. Mocini, M. Uguccioni, S. Strano, G. Imperoli and M. Santini for the ANMCO (Associazione Nazionale Medici Cardiologi Ospedalieri) Lazio - "Smoking Cessation Initiative".

Given the limited research on Italian hospital smoking care practices, a cross-sectional survey was undertaken in April-May 2011 to describe the current status of smoking cessation interventions for ACS patients in cardiovascular institutions of the Lazio Region of Italy. Lazio is a region of central Italy with a resident population of about $5,600,000$. According to the data of the Regional Health Authority, about $\mathbf{1 0 . 0 0 0}$ patients are admitted for ACS every year in this region of Italy. Acute cardiac care in the region is currently provided by 33 Cardiology Divisions. All of these units were considered as eligible for the survey. The eligible respondent for each unit was the director. A self-report questionnaire was developed based on previous studies that examined the specific features of smoking cessation care provided to hospitalised patients. Questionnaires were forwarded by the Lazio Regional Section of the Italian National Association of Hospital Cardiologists (ANMCO).

Completed questionnaires were received from 22 of the 33 eligible Divisions (66\%). These 22 responding units cur-
\end{abstract}

rently provide acute care to about $70 \%$ of all ACS patients of the region. Responding units were more likely to represent public non-teaching hospitals $(\mathrm{p}=\mathbf{0 . 0 0 2})$, while non-responders were mostly from private non-teaching institutions $(p=0.04)$. Response rates were not influenced by the presence of either interventional catheterization laboratory (Cathlab)or cardiac surgery within the hospitals.

The survey suggest that most of cardiology units fail to provide recommended smoking care interventions to ACS patients. In particular, brief smoking cessation advice before discharge represents the only systematically implemented approach in clinical practice ( 22 units; $100 \%$ ). Smoking cessation counselling is provided only in 9 units $(\mathbf{4 0} \%)$. Specific pharmacotherapy is prescribed in selected case only in about one third of units (7 units; 32\%), with varenicline being the preferred drug. Structural variables and organizational complexity have no influence on smoking care, as hospitals with Cathlab and cardiac surgery do not implement more effective strategies. Overall, this survey shows that the majority of smoking ACS inpatients may receive inadequate smoking care and that hospitals have considerable opportunity for improvement.

Keywords: Smoking cessation, Acute Coronary Syndromes, Cardiovascular Prevention.

Monaldi Arch Chest Dis 2012; 78: 85-88.

\footnotetext{
${ }^{1}$ Cardiovascular Department, San Filippo Neri Hospital, Rome, Italy.

2 Cardiology Division, CTO Hospital, Rome, Italy.

3 Department of cardiovascular and Respiratory Sciences, "Sapienza" University of Rome.

${ }^{4}$ Internal Medicine Department, San Filippo Neri Hospital, Rome, Italy.
}

Corresponding author: Furio Colivicchi; Viale Gorgia da Leontini, 330; 00124, Rome, Italy;

E-mail address:f.colivicchi@sanfilipponeri.roma.it; tel.+39.06.3306.2429; fax.+39.06.3306.2489

\section{Introduction}

Complete cessation of active tobacco smoking is associated with a significant $30-40 \%$ reduction in the relative risk of death after acute coronary syndromes (ACS) $[1,2]$. In light of these major benefits, active in-hospital and post-discharge interventions are currently recommended to assist smokers in quitting after ACS [3]. However, smoking cessation interventions appear to be largely underutilized in cardiovascular institutions providing acute care to ACS patients [4]. As a consequence, smoking relapse rates among smokers who have become abstinent during an admission for ACS may exceed $60 \%$ at 12 months from discharge [5].

Given the limited recent research on hospital smoking care practices, a survey was undertaken to describe the current status of smoking cessation interventions for ACS patients in a representative sample of Cardiology Divisions of the Lazio Region of Italy, which is a large area $\left(17,000 \mathrm{~km}^{2}\right)$ in central Italy with a resident population of about 5,600,000 [6]. 


\section{Methods}

A cross-sectional survey of smoking cessation interventions routinely delivered to ACS patients in Cardiology Divisions of acute care hospitals of the Lazio Region of Italy was undertaken in April-May 2011. Eligible services were those Cardiology Units within hospitals providing acute care to patients with ACS. The eligible respondent for each unit was the director, or a senior attending cardiologist.

A self-report questionnaire was developed based on recommendations included in the US Clinical Guidelines for Treating Tobacco Use and Dependence [7], and on previous reports that examined the specific features of smoking cessation care that can be provided to hospitalised patients $[8,9]$.

Smoking cessation interventions were then classified as:

1. Systematic behavioural interventions (brief advice, individual counselling, provision of selfhelp materials, group therapy).

2. Post-discharge support and follow-up.

3. Pharmacotherapy (such as nicotine replacement therapy, bupropion, varenicline)

A senior cardiologist pilot tested the survey structure and content, resulting in minor revisions before final distribution. Questionnaires were forwarded by the Lazio Regional Section of the Italian National Association of Hospital Cardiologists (ANMCO), which is the professional association of cardiologists working in public hospitals of the Italian National Health Service (www.anmco.it).

The survey assessed current smoking cessation interventions regarding ACS patients who were smokers, as well as hospital characteristics. Respondents were asked to complete the survey based on their knowledge of practices within their unit.

Hospitals were categorised according to the standard definitions of the Italian Cardiology Network [10]:

1. Group 1 - hospitals with only a coronary care unit (CCU),

2. Group 2 - hospitals with CCU and interventional catheterization laboratory (Cathlab),

3. Group 3 - hospitals with CCU, Cathlab and cardiac surgery

\section{Statistical analysis}

The prevalence of each type of smoking cessation intervention is reported as a proportion. Differences in the prevalence of such care strategies between different types of units were examined by $\chi^{2}$ or Fisher exact test as appropriate.

Logistic regression analysis was used to examine the potential associations between type of unit and specific smoking cessation interventions. Data analysis was performed by using the SPSS statistical software package (SPSS 12.0). $\mathrm{P}<0.05$ was considered statistically significant.

\section{Results}

Each year, in the Lazio Region of Italy about 10,000 people are hospitalised for ACS [11]. Besides, according to the Regional Health Authority, acute care for ACS in this administrative area is currently provided by 33 Cardiology Divisions [12]. All of these 33 units were considered as eligible for the survey. Completed questionnaires were received from 22 of the 33 eligible Cardiology Divisions (66\%). These 22 responding units currently provide acute care to about $70 \%$ of all ACS patients of the region [12]. Characteristics of responding and nonresponding divisions are provided in Table 1. Responding units were more likely to represent public non-teaching hospitals $(\mathrm{p}=0.002)$, while non-responders were mostly from private non-teaching institutions $(\mathrm{p}=0.04)$. Response rates were not influenced by the presence of either Cathlab or cardiac surgery within the hospitals as assessed by logistic regression analysis.

Table 2 summarises the prevalence of the various forms of smoking cessation intervention delivered to ACS patients in the responding units. Smoking care was not influenced by the presence of either Cathlab or cardiac Surgery as assessed by logistic regression analysis.

\section{Discussion}

This study reports the prevalence of smoking cessation interventions routinely delivered to ACS patients by acute care hospitals of a major Italian re-

Table 1. - Characteristics of responding and non-responding eligible hospitals (total number $=33$ )

\begin{tabular}{lcc}
\hline Public University hospitals - number (\%) & $\begin{array}{c}\text { Responders } \\
\mathbf{2 2} \text { hospitals }\end{array}$ & $\begin{array}{c}\text { Non-responders } \\
\mathbf{1 1} \text { hospitals }\end{array}$ \\
\hline Private University hospitals - number $(\%)$ & $1(4)$ & $2(18)$ \\
\hline Public non-teaching hospitals - number (\%) & $0(0)$ & $1(9)$ \\
\hline Private non-teaching hospitals - number $(\%)$ & $18(82)^{*}$ & $3(27)$ \\
\hline CCU only - number $(\%)$ & $3(14) \S$ & $5(46)$ \\
\hline CCU and Cathlab - number (\%) & $10(45)$ & $2(55)$ \\
\hline CCU, Cathlab and Cardiac Surgery - number $(\%)$ & $9(41)$ & $3(27)$ \\
\hline CCU, coronary care unit; Cathlab, interventional catheterization laboratory, * $\mathrm{p}=0.002 ; \S \mathrm{p}=0.04$ & $3(14)$ &
\end{tabular}


Table 2. - Provision of smoking cessation interventions in responding cardiology units

\begin{tabular}{|c|c|c|c|c|}
\hline & $\begin{array}{l}\text { Overall } \\
\text { sample } \\
22 \text { units }\end{array}$ & $\begin{array}{c}\text { CCU } \\
\text { only } \\
10 \text { units }\end{array}$ & $\begin{array}{c}\text { CCU and } \\
\text { Cathlab } \\
9 \text { units }\end{array}$ & $\begin{array}{c}\text { CCU, Cathlab } \\
\text { and CS } \\
3 \text { units }\end{array}$ \\
\hline \multicolumn{5}{|l|}{ General measures } \\
\hline Brief smoking cessation advice - number (\%) & $22(100)$ & $10(100)$ & $9(100)$ & $3(100)$ \\
\hline Smoking care indications in discharge letter- number $(\%)$ & $11(50)$ & $4(40)$ & $4(45)$ & $3(100)$ \\
\hline \multicolumn{5}{|l|}{ Counselling for smoking cessation } \\
\hline Individual counselling - number $(\%)$ & $8(36)$ & $2(20)$ & $4(45)$ & $2(66)$ \\
\hline With a single session - number $(\%)$ & $6(28)$ & $2(20)$ & $4(45)$ & $0(0)$ \\
\hline With multiple sessions - number $(\%)$ & $2(9)$ & $0(0)$ & $0(0)$ & $2(66)$ \\
\hline Delivered by physician - number $(\%)$ & $4(18)$ & $2(20)$ & $2(22)$ & $0(0)$ \\
\hline Delivered by nurse - number $(\%)$ & $4(18)$ & $1(10)$ & $1(11)$ & $2(66)$ \\
\hline Group counselling - number $(\%)$ & $1(4)$ & $0(0)$ & $1(11)$ & $0(0)$ \\
\hline \multicolumn{5}{|l|}{ Other behavioural interventions } \\
\hline Provision of self-help materials (booklets) - number (\%) & $4(18)$ & $2(20)$ & $1(11)$ & $1(33)$ \\
\hline Follow-up support for smoking cessation after discharge - number (\%) & $7(32)$ & $2(20)$ & $3(33)$ & $2(66)$ \\
\hline \multicolumn{5}{|l|}{ Pharmacotherapy } \\
\hline Systematic prescription - number $(\%)$ & $0(0)$ & $0(0)$ & $0(0)$ & $0(0)$ \\
\hline Prescription in selected cases - number $(\%)$ & $7(32)$ & $2(20)$ & $3(33)$ & $2(66)$ \\
\hline NRT - number $(\%)$ & $1(4)$ & $1(10)$ & $0(0)$ & $0(0)$ \\
\hline Bupropion - number (\%) & $1(4)$ & $1(10)$ & $0(0)$ & $0(0)$ \\
\hline Varenicline - number $(\%)$ & $7(32)$ & $2(20)$ & $3(33)$ & $2(66)$ \\
\hline
\end{tabular}

$\mathrm{CCU}$, coronary care unit; Cathlab, interventional catheterization laboratory; CS, cardiac surgery; NRT, nicotine replacement therapy

gion. The results suggest that most of cardiology units fail to provide recommended smoking care interventions to ACS patients. In particular, brief advice represents the only systematically implemented approach in clinical practice, while only about $40 \%$ of respondents reported the provision of individual or group smoking cessation counselling. Furthermore, specific pharmacotherapy is prescribed in selected cases only in about one third of units, with varenicline being the preferred drug.

Another point of interest in that structural variables and organizational complexity seem to have no influence on smoking care, as hospitals with Cathlab and cardiac surgery do not implement more effective strategies.

The health care system is a key channel for delivering interventions to reduce tobacco use, which is the leading preventable cause of death in western countries and a major risk factor for cardiovascular disease. Consequently, a hospitalisation for a major cardiovascular event should always be considered a unique opportunity to deliver a structured smoking cessation intervention. However, this survey shows that the majority of smoking ACS inpatients may receive inadequate smoking care and that hospitals have considerable opportunity for improvement.

Overall, the results of this survey further suggest that healthcare providers should take smoking cessation interventions more seriously, as recommended treatments are not making their way into practice. As recommended, a successful program to help ACS patients quit smoking should take a comprehensive long-term approach, including individual counseling, post-discharge support and pharmacological treatment.

\section{References}

1. Wilson K, Gibson N, Willan A, Cook D. Effect of smoking cessation on mortality after myocardial infarction. meta-analysis of cohort studies. Arch Intern Med 2000; 160: 939-44

2. Critchley JA, Capewell S. Mortality risk reduction associated with smoking cessation in patients with coronary heart disease: a systematic review. JAMA. 2003; 290: 86-97.

3. Krumholz HM, Anderson JL, Bachelder BL, et al. ACC/AHA 2008 performance measures for adults with ST-elevation and non-ST-elevation myocardial infarction: a report of the American College of Cardiology/American 
Heart Association Task Force on Performance Measures (Writing Committee to Develop Performance Measures for ST-Elevation and Non-ST-Elevation Myocardial Infarction). Circulation. 2008; 118: 2598-2648.

4. Dawood N, Vaccarino V, Reid KJ, Spertus JA, Hamid N, Parashar S. Predictors of smoking cessation after a myocardial infarction. The role of institutional smoking cessation programs in improving success. Arch Intern Med 2008;168:1961-7.

5. Colivicchi F, Mocini D, Tubaro M, Aiello A, Clavario P, Santini M. Effect of smoking relapse on outcome after Acute Coronary Syndromes. Am J Cardiol 2011; 108: 804-8.

6. http://www.regione.lazio.it/statistica/ accessed 15 July 2012.

7. Fiore MC, Jaen CR, Baker TB. Treating tobacco use and dependence: 2008 update. Clinical practice guideline. Rockville, MD: U.S. Department of Health and Human Services. Public Health Service; 2008.
8. Rigotti NA, Munafo MR, Stead LF. Interventions for smoking cessation in hospitalised patients. Cochrane Database Syst Rev 2007; CD001837.

9. Rigotti N, Munafo MR, Stead LF. Smoking cessation interventions for hospitalized smokers: a systematic review. Arch Intern Med 2008; 168: 1950-60.

10. Di Chiara A, Fresco C, Savonitto S, et al. Epidemiology of non-ST elevation acute coronary syndromes in the Italian cardiology network: the BLITZ-2 study. Eur Heart $J$ 2006; 27: 393-405.

11. Colivicchi F, Di Roma A, Uguccioni M, et al. Prevenzione cardiovascolare secondaria dopo sindrome coronarica acuta nella pratica clinica. Documento di Consenso delle Società Scientifiche di Medicina Cardiovascolare e Medicina Interna della Regione Lazio. G Ital Cardiol 2010; 11(Suppl 4): 3S-29S.

12. http://www.epidemiologia.lazio.it/vislazio/vis index it.php accessed 9 July 2012. 